\title{
La importancia de los elementos descriptivos en el relato de los hechos en Expeditio Persica de Jorge de Pisidia (III. 225-280)
}

\section{María Cristina Silventi}

Universidad Nacional de Cuyo, Argentina

silventicris@gmail.com

\section{Resumen}

En la sociedad bizantina la lectura en público era algo común. Quien estaba a cargo de esta era consciente de su influencia en el auditorio. El texto bien elaborado y la expresividad del orador eran fundamentales. En este trabajo nos

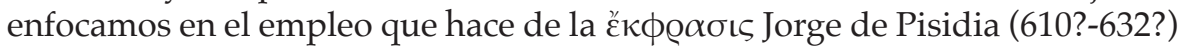
en un fragmento de Expeditio Persica, (vv. 225-280), en donde relata la parte final de la primera campaña del emperador Heraclio (610?-641), con el propósito de cautivar la atención de la elite cortesana que lo rodeaba enalteciendo su figura como representante de la fe cristiana.

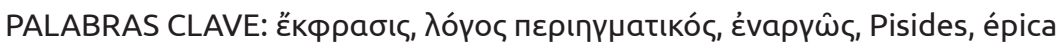
bizantina

The importance of the descriptive elements in the story of the facts in Expeditio Persica by George of Pisidia (III. 225-280)

\begin{abstract}
In Byzantine society, reading in public was common. Who was in charge of this was aware of its influence in the auditorium. The well-crafted text and the expressiveness of the speaker were fundamental. In this paper we focus on

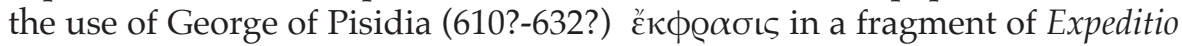
Persica, (vv. 225-280), where he recounts the final part of the first campaign of the Emperor Heraclius (610?-641), with the purpose of captivating the attention of the courteous elite that surrounded him, exalting his figure as a representative of the Christian faith.
\end{abstract}

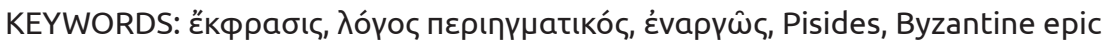




\section{La narración descriptiva}

La ع̌кф@ $\alpha \sigma \iota \varsigma$ ha sido un tema largamente debatido desde la antigüedad hasta nuestros días. Los primeros autores del siglo XX que retomaron el término e iniciaron teorías modernas fueron Leo Spitzer (1955) ${ }^{1}$ y Jean Hagstrum (1958). ${ }^{2}$ Ambos circunscribieron su campo a textos que describían obras de arte y, desde esta perspectiva, han partido muchos estudiosos de las artes plásticas en la actualidad. ${ }^{3}$ Sin embargo, el término estuvo planteado desde sus comienzos teóricos entre las dos categorías: la narrativa y la descriptiva " "[...] and was often a vivid and detailed narration of events" (Webb, 1999:64). Es decir que la

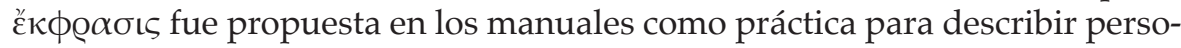
nas, lugares, batallas (que implicaba narración también), sin limitarse a objetos (Cristensen, 2009:7). El ejemplo más antiguo de descripción en movimiento

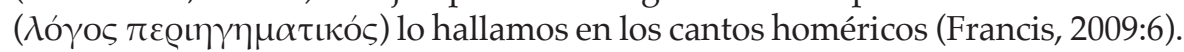
Esta interrelación de lo descriptivo y lo narrativo actualmente es observada en los estudios narratológicos. ${ }^{5}$ Según Koopman, más que hablar de texto narrativo o texto descriptivo, en relación con la ع̌k $\phi \varrho \alpha \sigma \iota \varsigma$, es conveniente analizar los elementos de ambos de manera indistinta: "[...] an ekphrasis may contain prototypical narrative elements and at the same time prototypical descriptive elements" (2014:53). Más adelante, explica cómo va abordar el estudio

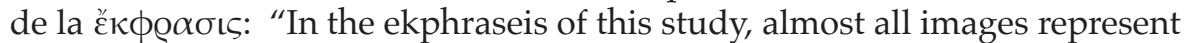
figures engaged in actions -in other words, the images represent some kind of narrative" (2014:55).

Siguiendo la hipótesis de análisis propuesta por este autor, trataremos de abordar el fragmento que hemos seleccionado: Expeditio Persica III. 225-280 de Jorge de Pisidia.

La Expeditio Persica es un poema estructurado en tres cantos que celebra la primera campaña del emperador Heraclio (622-623) y el fragmento seleccionado narra la derrota del regimiento persa. Producto de una comisión imperial, el objetivo principal de este poema era promover la moral entre los bizantinos realzando la figura del estratega como emblema del triunfo del cristianismo sobre el paganismo.

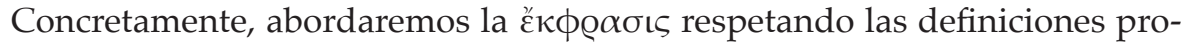
puestas por los primeros oradores en sus Поo $\gamma v \mu v \alpha ́ \sigma \mu \alpha \tau \alpha$, en los que el término no solo contemplaba la descripción de un objeto en particular, sino que podía ser utilizado para describir los hechos narrados en su desarrollo. Lo descriptivo entrelazado con lo narrativo 'contaba' a través de las imágenes en movimiento un determinado acontecimiento (dentro de un contexto histórico-social) y de este modo promovía en los oyentes una participación imaginativa y emocional. ${ }^{6}$

1 Cfr. Spitzer (1962:72); Webb (1999:16-17); Elsner (2002:2).

2 Hagstrum (1958:26).

3 Cfr. Elsner (2002:2).

4 Aunque algunos oradores, como Nicolás de Mira (siglo V) lo consideraron como género independiente. Sobre este tema: cfr. Felten (1913:70); Barthes (1989:143); González Rendón (2008:271); D’Angelo (1998:441).

5 Cfr. Genette (1989:156-157; 220-221); Bourbouhakis; Nilsson (2010:24). No obstante entre los narratólogos sigue prevaleciendo la clásica separación entre texto descriptivo y texto narrativo: cfr. Bal (1990:134135, 154); Genette (1998:12, 204); de Jong (2014:1); Fowler (1991:25-26).

6 El enfoque de la descripción animada y detallada, que ponderaba las imágenes frente a los ojos del receptor, ya se ve en la Retórica de Aristóteles (ver infra). Cfr. Webb (2009:195); Heffernan (1993:11); Manieri (1998:183). 


\section{El uso de las formas verbales finitas y no finitas ${ }^{7}$}

En los versos seleccionados, existe un predominio del pretérito imperfecto conjugado, le sigue el presente y luego una gran cantidad de participios e infinitivos. Según Koopman (2014:104), la importancia del uso del imperfecto se vincula estrechamente con la característica principal del texto, pues permite al narrador describir los acontecimientos en movimiento y esto hace a la particularidad de la č́ $\phi \varrho \alpha \sigma \iota \varsigma$, en la cual lo narrado no se separa de lo que se describe, sino que lo complementa.

Respecto del uso de las formas nominales, vemos que desde el verso 225 hasta el 229 se suceden participios destinados a describir la situación de los persas:

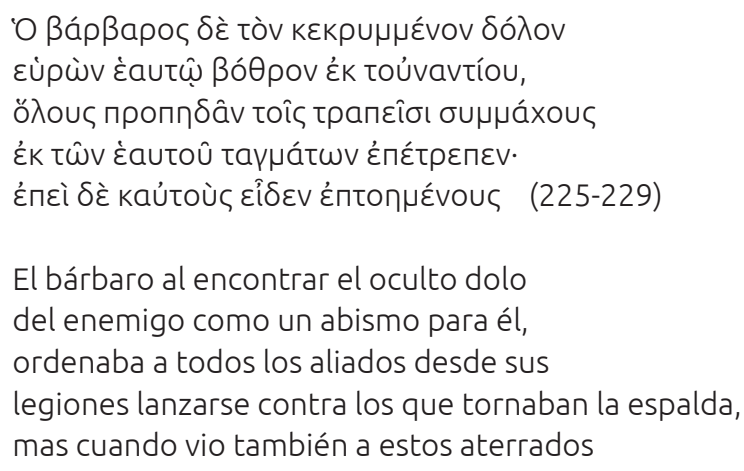

Es interesante detenerse en cada uno. En el verso 225 utiliza el participio per-

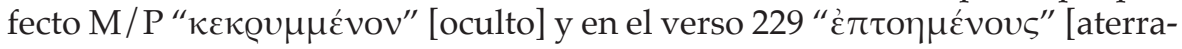
dos], en ambos casos como adjetivos de dos sustantivos relevantes: "ठó $\lambda o v$ " y " $\beta \alpha ́ \varrho \beta \alpha \varrho o \varsigma^{\prime}$. El primero hace referencia al engaño urdido por Heraclio haciéndole creer a Shahrbaraz que sus hombres huían para incitarlos a que salieran a perseguirlos. El segundo describe el estado del enemigo ante la sorpresa. En los dos casos, los participios expresan las consecuencias en la situación presente. El mismo valor del participio perfecto M/P lo podemos ver en el

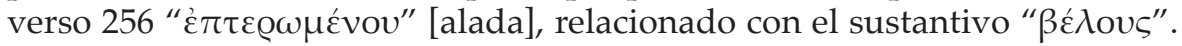
Conviene observar la imagen dentro de los versos 256 al 258 para entender su fuerza expresiva:

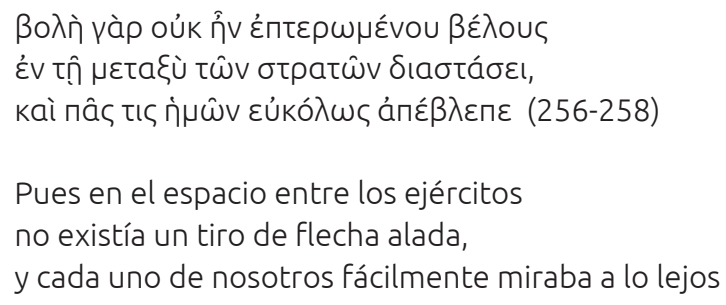

En este caso, también expresa una consecuencia presente, el poeta coloca en primer plano la imagen del orden de las filas bizantinas en una disposición perfecta, como el resultado de la excelente diligencia de quien los conduce. De una manera indirecta, esta imagen sirve para resaltar la habilidad del estratega como conductor de sus hombres. Este contraste entre los dos ejércitos ejerce una influencia concluyente en el auditorio. 
Tras vincular este pasaje por la similitud de valores de los participios empleados, volvemos a nuestra línea expositiva. En el verso 226 encontramos el participio aoristo " $\varepsilon v ́ \varrho \omega ́ v$ ". Respecto del uso del participio y del infinitivo, Koopman dice lo siguiente: "The events are marked by their verbal forms (aorist participle, infinitive) as anterior and posterior to the ongoing events" (2014:121). Y unas páginas más adelante, continúa: "By using an aorist participle, the narrator can refer to an event that is anterior to the events depicted in the image." (2014:125). Es decir que constituyen dispositivos narrativos que permiten extenderse más allá del momento presente de lo narrado para inferir lo que no está visible (ya observado por Lessing en su Laocoonte, 1960:118-124). ${ }^{8}$

En este verso, el participio " $\varepsilon v ́ \varrho \omega ́ v$ " menciona una acción anterior a la toma de decisión por parte del jefe persa, pues ha sido sorprendido por la inesperada estrategia de Heraclio. Lo mismo ocurre con la forma poética "

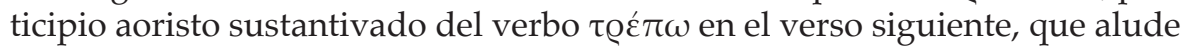
concretamente a la acción de los bizantinos, de fingir la huida, pergeñada la noche anterior.

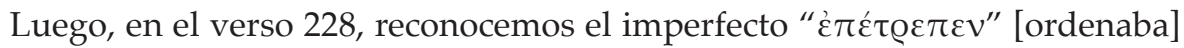
con toda su fuerza aspectual, porque presenta la imagen de un estratega sorprendido que reitera en vano la orden de atacar. Esta acción repetitiva, aletarga el tempo de los acontecimientos desgastando, ante quienes escuchan el poema, la imagen aguerrida de los hombres de Shahrbaraz. El aoristo " $\varepsilon i \tilde{\delta} \varepsilon v^{\text {" [vio] }}$ del verso siguiente, quiebra abruptamente ese estado de inercia en el que los

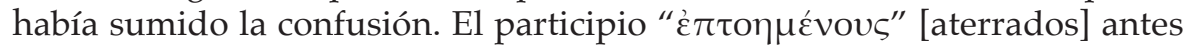
mencionado, está colocado inmediatamente después de este verbo conjugado y se relaciona con el sustantivo que comienza el fragmento que nos concierne:

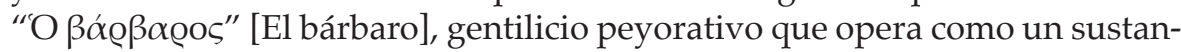
tivo colectivo y que concentra la atención de la audiencia. El verso siguiente desglosa el sentimiento expresado por este participio perfecto y describe sus

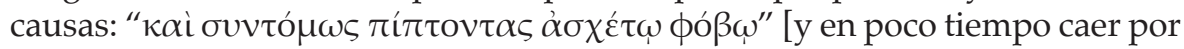

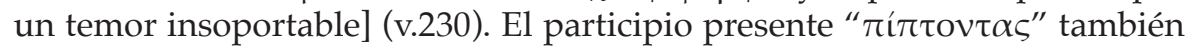
vinculado con el aoristo " $\varepsilon i \tilde{\delta} \varepsilon \varepsilon v^{\prime}$, refuerza la idea de un sentimiento que invade y toma posesión de sus voluntades. (Este concepto es común en la antigua épica y la lírica arcaica, cuyo pensamiento diverge del de nuestro autor cristiano, responsable de sus actos y sentimientos, frente a los persas, capaces de rene-

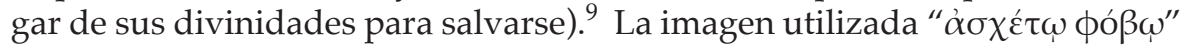
ilustra el estado de desatino extremo que sufren los bárbaros y que arrastrará al rey persa a una serie de acciones desafortunadas:

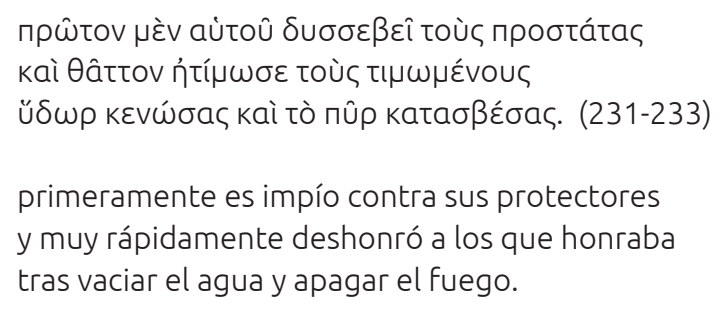

A partir del verso 231 predomina el presente, que destaca las acciones llevadas a cabo por Shahrbaraz. De manera gradual, nuestro poeta narra los hechos y logra un crescendo dramático. Así, el estratega persa se vuelve contra sus

8 Beaujour (1981:36). 


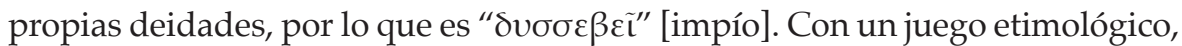

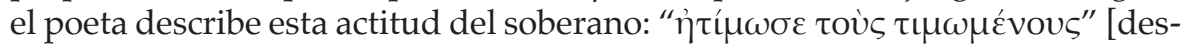
honró a los que honraba], en donde el aoristo activo destaca la acción decidida y el participio perfecto $\mathrm{M} / \mathrm{P}$ marca el abandono del rito, resaltado también por los dos participios de aoristo del verso siguiente: " $\kappa \varepsilon v \omega \omega \sigma \alpha \varsigma^{\prime}$ [ [tras vaciar], y "к $\kappa \tau \alpha \sigma \beta \varepsilon ́ \sigma \alpha \varsigma^{\prime}$ " [apagar]. En nota a pie de página 118, Tartaglia comenta la ironía del poeta sobre el uso que hacen los persas de los elementos (agua y fuego) que adoraban como divinidades (1988:125). Evidentemente, la ironía se suma al recurso de la ékф@ $\alpha \sigma \iota \varsigma$ para resaltar la figura del emperador y es un claro mensaje en contra del paganismo persa, cuyos dioses se relativizan en situaciones extremas para tornarse en meros instrumentos utilitarios.

El presente activo, así como el participio y el infinitivo del mismo tiempo, utilizados en los versos 234-239, llevan ante la audiencia los movimientos del jefe persa:

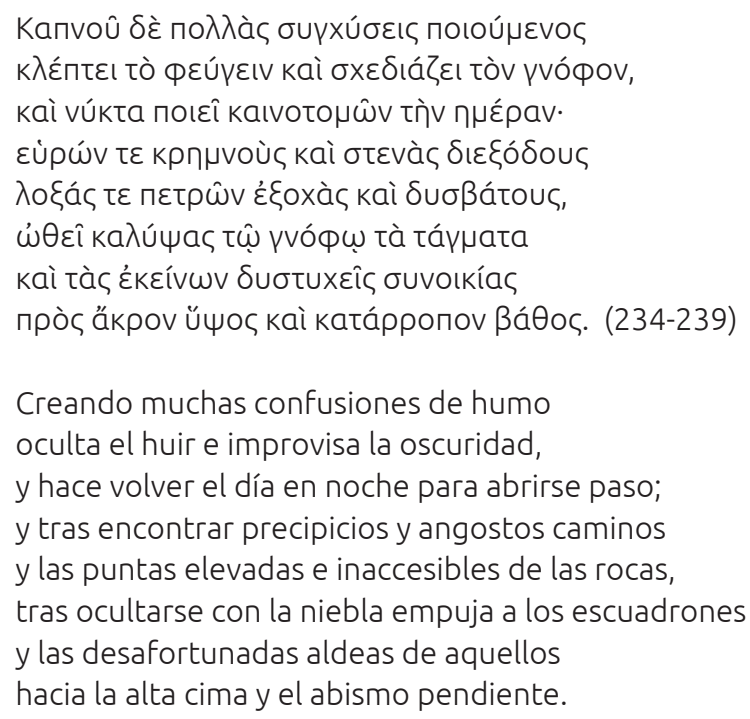

El estratega bárbaro reniega de sus divinidades con un único propósito: generar caos para favorecer 'su' huida sin tener en cuenta la seguridad de sus propios hombres. Las acciones expresadas, ya en presente, ya en formas nominales,

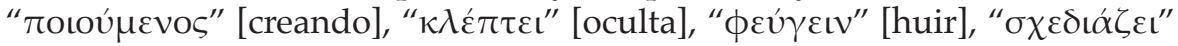

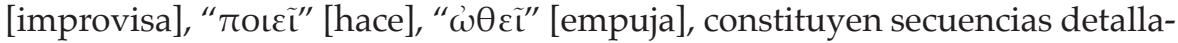
das de un solo pasaje. Por otra parte, la utilización de imágenes como "K $\alpha \pi v$ ve

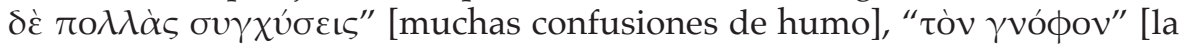
oscuridad], sugiere un panorama lúgubre, muy vinculado con el estado sombrío del enemigo.

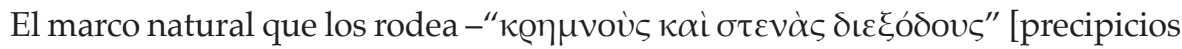

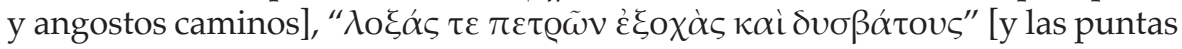
elevadas e inaccesibles de las rocas]- ocasiona confusión entre los persas y saca lo peor de Shahrbaraz, que, sin ningún escrúpulo, los empuja para salvarse solamente él. Los dos versos siguientes ilustran las condiciones a las que son arrastrados por su propio señor. El estupor y el temor generan un violento y desesperado desorden entre ellos. Mediante el recurso de la acumulación, tanto de palabras como de imágenes, el público receptor puede inferir la situación como si la estuviera presenciando.

Los siguientes diez versos describen narrando tal situación: 


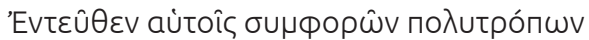

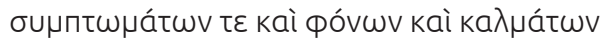

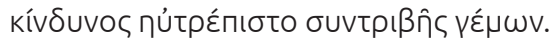

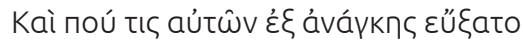

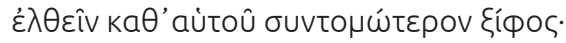

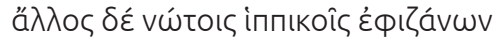

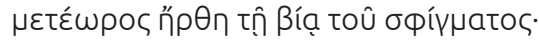

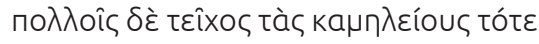

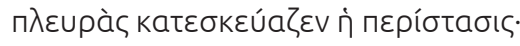

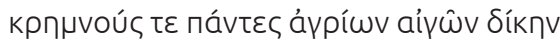

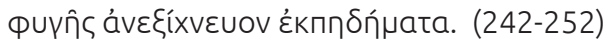

Entonces el peligro, cargado de muy variadas desgracias y desdichas y matanzas y ruinas, los disponía al arrepentimiento. Y en algún lugar uno de ellos por necesidad suplicó que la espada más rápida sobre él llegara, mas otro, sentado sobre los lomos de los caballos inestable, fue destruido por la violencia del apriete. Y a muchos entonces la situación les aparejaba como un muro los flancos de los camellos y todos, a la manera de cabras salvajes, buscaban lugares escarpados como saltos de huida.

Los aoristos describen ya sea la reacción naturalmente humana de conserva-

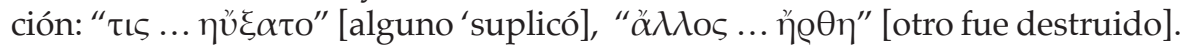
Mientras que el imperfecto abarca las acciones continuas de la multitud persa:

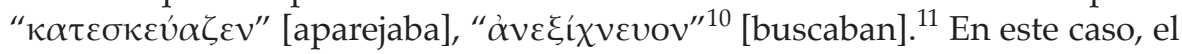
uso del imperfecto logra expresar la idea de confusión a través de una acción repetitiva que presenta a la audiencia el remolino humano que gira sin sentido

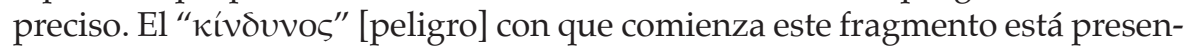
tado como una especie de poder devastador que los arrastra. La disposición de este sustantivo, luego de haberse enumerado sus características en los versos anteriores, introducidas por el participio presente " $\gamma \varepsilon \dot{\varepsilon} \mu \omega v^{\text {" [cargado] y cuyos }}$ genitivos régimen permiten la enumeración de esas características a través del

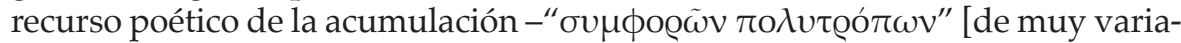

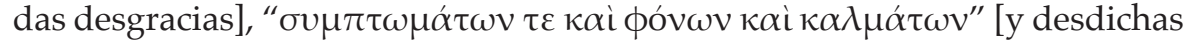
y matanzas y ruinas]-, logra ese efecto visual y vívido de una fuerza sombría que se apodera del ánimo de la multitud. El sustantivo " $\kappa i ́ v \delta v v o \varsigma^{\prime \prime}$ [peligro]

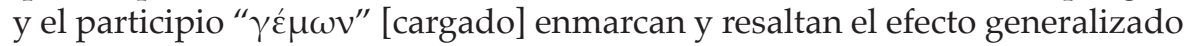

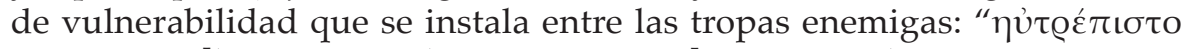
$\sigma v v \tau \varrho \iota \beta \tilde{\eta} \varsigma^{\prime \prime}$ [los disponía al arrepentimiento] y en este solo verso queda centrada la idea de la debilidad del poderío persa.

Es de destacar cómo el poeta compara a los persas en el verso 251, con " $\alpha \gamma \varrho i ́ \omega v$ $\alpha \hat{\imath} \gamma \tilde{\omega} v^{\prime \prime}$ [cabras salvajes], y en otras partes del poema, con otros animales: " $\alpha \hat{i}$

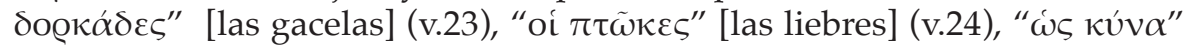

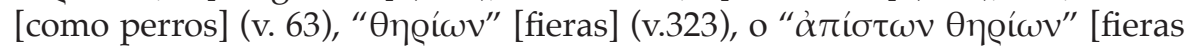
impías] (v. 330), siempre dándoles a los términos una fuerte carga peyorativa que degrada a la raza enemiga. Este menosprecio involucra al público, porque

10 ăna६. Cfr. Trapp (2001:102).

11 En el verso 244 vemos el uso del pluscuamperfecto M/P "пútрع́nıбto", que puede ser traducido como un imperfecto. Cfr. Browning (1983:29-30); Sánchez Egea (2017:376). 
los hechos narrados son actualizados mediante la referencia a realidades conocidas por este. Con palabras de Manieri: "[...] tratta dall'esperienza comune e dall'osservazione diretta della natura, della vita degli animali e degli uomini" (1998:188).

Desde el verso 253 hasta el 280 dos cuadros contrapuestos son presentados ante la audiencia: el ejército bizantino y el ejército bárbaro. También aquí se utilizan principalmente verbos conjugados en imperfecto y presente, además de formas nominales en presente.

Los referidos al ejército bizantino sugieren estabilidad, orden: " $\beta \lambda \varepsilon ́ \tau o v \tau \varepsilon \varsigma$ "

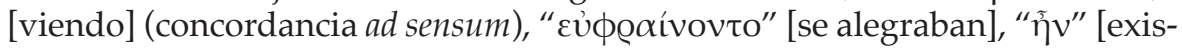

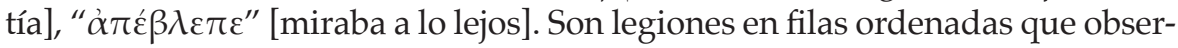
van el tumulto persa. En cambio, con respecto al ejército adversario, describen

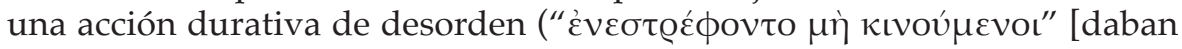
vueltas sin moverse]) y sirven también para introducir una extensa comparación con el mar, que analizaremos a continuación.

A modo de síntesis de este apartado podemos decir que: (a) el uso del pretérito imperfecto potencia su aspecto durativo e ilustra las acciones mientras transcurren, pero, además crea un 'tempo' de indefinición y lentitud; (b) el aoristo contrasta con acciones puntuales la inercia en la que se ve sumida la multitud persa; (c) el presente conjugado, así como sus formas nominales contribuyen a dar la sensación al auditorio de estar presenciando el sitio de los persas y a aumentar el dramatismo de la situación; (d) el participio perfecto M/P es utilizado para expresar las consecuencias en la situación presente narrada y (e) los participios e infinitivos aoristos son utilizados para hacer referencia a un hecho que sucedió antes de lo que se está contando.

\title{
3. El mar tempestuoso y los persas
}

Sobre la importancia del paisaje en lo narrado afirma Gregory:

\begin{abstract}
Someone conversant with the theories of narrative, however, will note that individuals in the Byzantine period would presumably have interpreted their own personal and local landscape -the things they saw every day- along lines drawn up by the society as a whole, and there is no reason to doubt that the sacred landscape (or perhaps better, the transformed nature of the sacred landscape) was perceived by ordinary people as much as by learned theologians and ecclesiastical officials. (2017:486-487).
\end{abstract}

Sin duda la fuerza de la imagen del paisaje marino, tan familiar entre los bizantinos, hace más vívidas las acciones de la batalla, porque se vincula con la experiencia personal que el auditorio tiene del espacio y esto ejerce una influencia decisiva en él. ${ }^{12}$ Ilustrar a través de una comparación con el mar tempestuoso la tremenda confusión de los persas, en su intento de huida, es más elocuente que una narración de los hechos despoblada de imágenes.

El uso del imperfecto y el presente (activo y participios) trae ante la vista de la audiencia el momento más crítico de la batalla; y el recurso de la comparación 
ilustra las imágenes que son presentadas como pinturas en serie o, como afirma Koopman, como en un comic (2014:137). Veamos en detalle cómo se vincula el paisaje marino con ambos bandos:

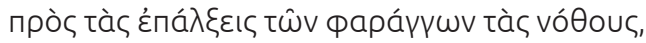

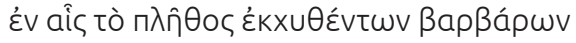

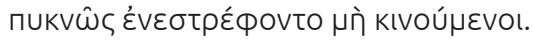

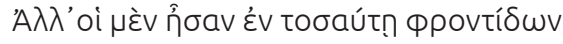

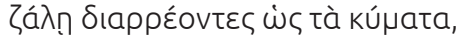

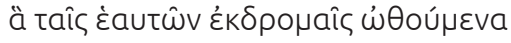

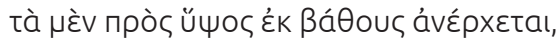

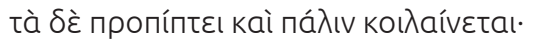

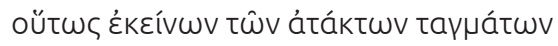

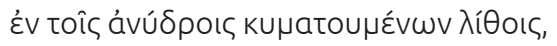

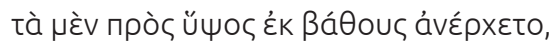

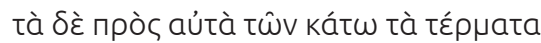

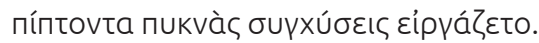

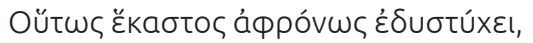

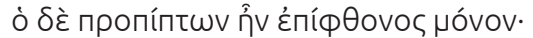

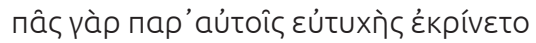

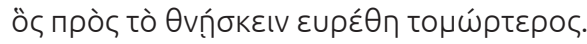

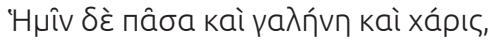

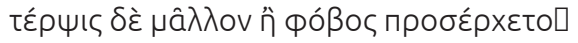

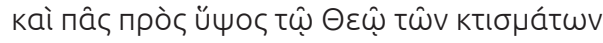

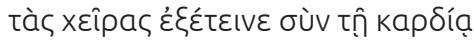

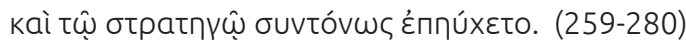

hacia las falsas defensas de los precipicios, en las que la multitud de los bárbaros desparramados se revolvía (daba vueltas) compactamente sin moverse. Pero ellos estaban en tal tempestad de preocupaciones, esparciéndose como las olas, que, siendo empujadas en sus mismas salidas, unas hacia la cima desde la profundidad se elevan, otras se arrojan y de nuevo se vacían; así agitándose aquellos regimientos desordenados entre las rocas sin agua, unos hacia la cima desde el abismo se elevaban, otros, hacia los mismos límites de los de abajo cayendo, provocaban reiteradas confusiones. Así cada uno fracasaba insensatamente, el que caía solamente era envidiado, pues era considerado afortunado por ellos todo quien fuera encontrado más preciso para morir. Mas para nosotros toda la calma del mar y la gracia y el encanto llegaban más que el temor, y todo hombre hacia la cima por el Dios de las creaturas extendía las manos junto con el corazón y alababa a su estratego con ardor.

Los tres primeros versos de este fragmento presentan al enemigo acorralado. La imagen de dar vueltas sin moverse, anteriormente destacada (" $\pi v \kappa v \tilde{\omega} \varsigma$

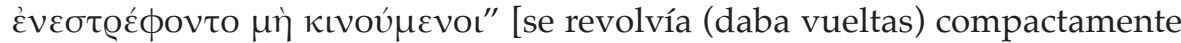
sin moverse]), expresa a través del imperfecto y el participio (concordancia ad sensum) un estado contradictorio de quietud y movimiento. Por otra parte, el 
adverbio " $\pi v \kappa v \tilde{\omega} \varsigma$ " [compactamente] presenta a la multitud como un todo, como una masa humana indiferenciada. Con respecto a la multitud descripta en las batallas, afirma Koopman: "The figures engaged in the actions depicted are mostly in the plural and anonymous. [...] Furthermore, such non-human figures are typically found in battle scenes" (2014:137).

Ahora bien, el siguiente verso comienza con la conjunción adversativa " $\mathrm{A} \lambda \lambda$ ”" que delimita la comparación desde el verso 262 hasta el verso 280, que podemos dividir, a su vez, en dos situaciones contrapuestas: la primera (vv. 262275), es la turbulencia del mar y de los persas, la segunda (vv. 276-280, es la serenidad del mar y de los bizantinos.

Veamos en detalle cada parte. Entre los versos 262 y 275 se nos describe la situación crítica de los persas. La borrasca es la materialización del miedo y

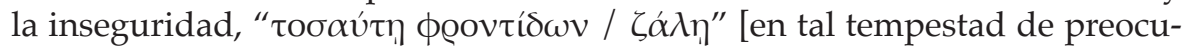

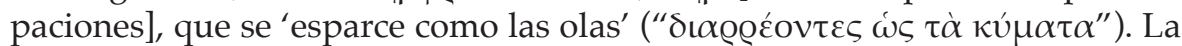
acumulación de verbos en presente ilustra el movimiento impetuoso de las

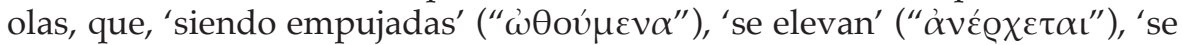

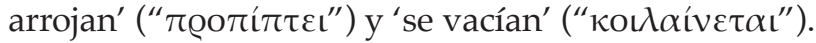

Con el adverbio "oú $\tau \omega \varsigma^{\prime \prime}$ (v. 267), el poeta introduce el elemento real de la

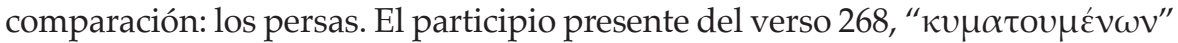
[agitándose], los presenta en una situación límite. Obsérvese la repetición del lexema en la raíz del participio y el sustantivo " $\kappa u ́ \mu \alpha \tau \alpha$ " [olas], que los interrelaciona y asegura la eficacia de lo que se describe. ${ }^{13}$ Por otra parte, existe una absoluta correspondencia entre los versos 265 y 266, que describen el movimiento impetuoso de las olas, y los versos 269 y 270 , que trazan con la misma disposición paralela, la marea humana que se dispersa desordenadamente.

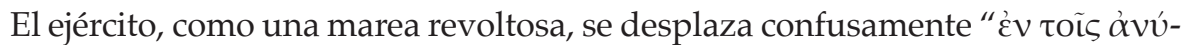

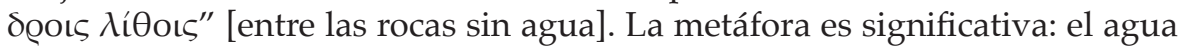
ahora es la multitud de soldados. La reiteración de los pronombres correlacio-

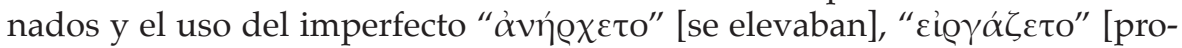
vocaban], así como el participio presente " $\pi$ í $\tau \tau$ ov $\tau \alpha$ [cayendo]" (vv. 269-271, causan el efecto buscado de acción ininterrumpida y repetitiva. Se reafirma la comparación nuevamente con el uso del adverbio "Oú $\tau \omega \varsigma^{\prime \prime}$ que introduce el

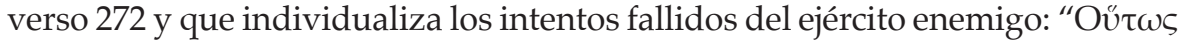

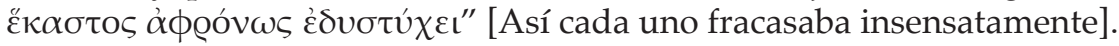

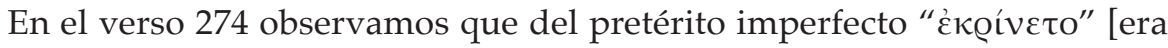
considerado] dependen dos subordinadas dispuestas de tal manera que enmarcan la proposición principal. Ambas se refieren a la muerte: "ó $\delta \dot{\varepsilon} \pi \varrho o \pi i ́ \pi \tau \omega \nu$

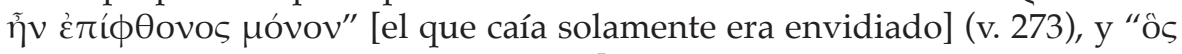

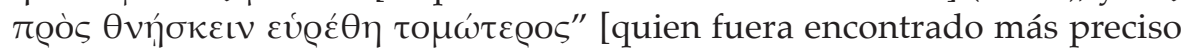
para morir] (v. 275. El sentido de ambas proposiciones sólo se completa con el verso 274, que al verbo ya referido le agrega un predicativo clave para los tres

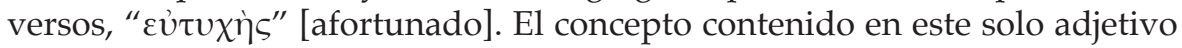
describe con ironía la situación paradójica de los persas, pues, aunque temen morir, ven afortunado al que muere.

La segunda parte de la comparación (vv. 276-280, también está referida al mar, pero esta vez, en calma. Tres sustantivos describen el estado de gracia 
en el que se encuentran los hombres de Heraclio: " $\gamma \alpha \lambda \eta ́ v \eta$ " [calma del mar\},

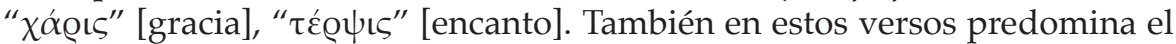

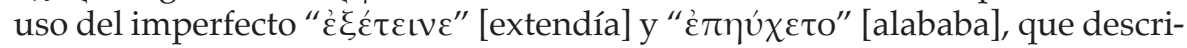
be la acción continua de gratitud y alabanza y, al mismo tiempo, aletarga las secuencias para reunir en una sola imagen simbólica al ejército piadoso que loa a Dios a través de su estratega.

\section{Los adjetivos como elemento descriptivo fundamental}

Es interesante dedicarle un apartado a la utilización de los adjetivos y su influencia en el relato. Vemos, en primer lugar, una mayoría notable referida a los persas y, especialmente en este fragmento, vinculada a la situación extrema a la que están expuestos. A todos estos adjetivos podemos agruparlos en una misma sensación de oscuridad, temor e inseguridad.

Así, por ejemplo, en el verso 230, la primera impresión que tiene el enemigo de haber caído en la trampa urdida por Heraclio, está concentrada en la fuerte sensación que expresa el adjetivo " $\alpha \sigma \chi \chi \varepsilon ́ \tau \omega$ " [insoportable] y que mensura la intolerable dimensión del " $\phi o ́ \beta \omega$ " [temor], como una potencia que se precipita sobre todos y los inmoviliza (esta noción del miedo como impuesto desde fuera ya lo hemos mencionado antes, cuando hablamos del sentimiento que los invade y toma posesión de sus voluntades, muy característico de la época

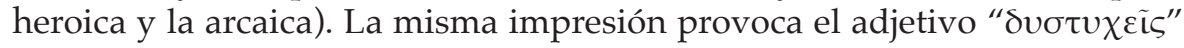
[desafortunadas] del verso 240 relacionado con el sustantivo "бvvoıkí $\alpha \varsigma^{\prime \prime}$ [tiendas]. El recurso de la personificación logra profundizar aún más esa sensación de desasosiego que los agobia, porque se extiende inclusive a los objetos familiares que los rodean. En otras dos oportunidades nuestro poeta utiliza

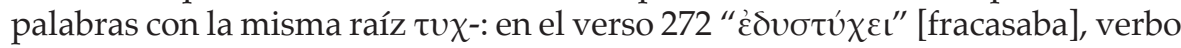
introducido por el adverbio "Oú $\tau \omega \varsigma^{\prime}$ " que, a modo de colofón, cierra la com-

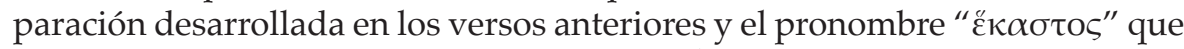
particulariza la percepción de derrota de los hombres. Luego la encontramos en el verso 274 " $\varepsilon \dot{v} \tau \cup \chi \eta े \varsigma$ " [afortunado] comentado como paradoja irónica en el

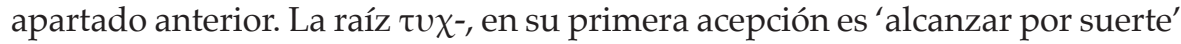
(Eterovic, 1970:315). No es casualidad que se reitere o en su forma verbal o como sustantivo ya sea con significación positiva o negativa. Más allá de su fuerte resonancia en el interior de los versos, está recalcando irónicamente la situación en la que están comprometidos los persas debido al brusco cambio de las circunstancias y repercute en los oídos del público receptor como un mensaje claro: los persas han perdido su supremacía. Por primera vez se impone la fe cristiana sobre los bárbaros.

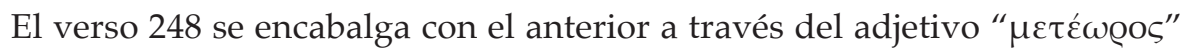
[inestable] y se relaciona con el pronombre indefinido " $\alpha \not \lambda \lambda o \varsigma^{\prime}$ [ [otro], que, a su vez, eslabona la serie de reacciones de los hombres de Shahrbaraz ante la derrota. El guerrero persa, acostumbrado a montar y desplazarse sobre el caballo en los enfrentamientos, se siente " $\mu \varepsilon \tau \varepsilon \dot{\varepsilon} \omega \varrho \varsigma^{\prime}$ " [inestable]. Esa inseguridad del jinete se traslada al animal, que gira y tropieza con los de su especie y se convierte en una trampa mortal para ambos.

La maestría del poeta para ubicar los adjetivos de manera de hacer más vívida la situación tan dispar entre uno y otro bando y, de este modo, comprometer a su auditorio con el relato, la apreciamos también en las siguientes construc-

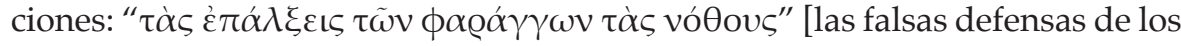




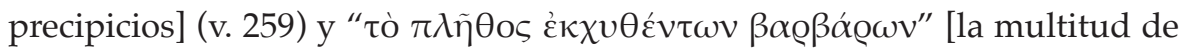
los bárbaros desparramados] (v. 260). Ambas imágenes son observadas desde lejos por el ejército bizantino y esta perspectiva también es compartida por el auditorio y el narrador durante la recitación. La ironía se cuela a través del adjetivo "vó $\theta$ ous" [falsas] referido a las defensas y del participio aoristo pasivo

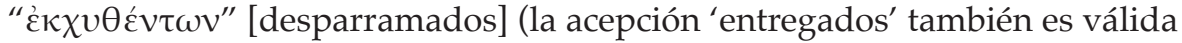
en V.P. y seguramente conocida por el público receptor), que describe el estado en el que se encuentran los persas. La clave está en presentar la situación como un espectáculo generado por ellos mismos. Al buscar lugares escarpados como protección, han generado su propio sitio, pues se han rodeado de precipicios y lo que intentaron que fueran sus defensas será la causa de su derrota.

Esta sensación de un abismo sin salida y de defensas inservibles ha venido anticipándose en versos anteriores a través de predicativos objetivos estratégicamente colocados para expresarla gradualmente. En primer lugar, el abismo

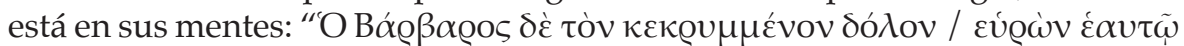

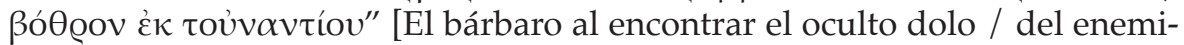
go 'como un abismo' para él] (vv. 225-226); en segundo lugar, se presenta la

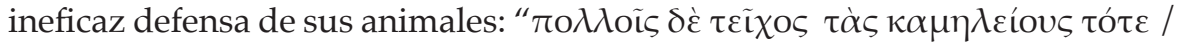

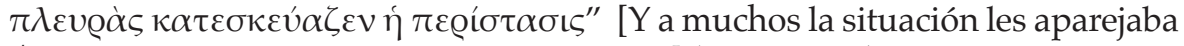
/ 'como un muro' los flancos de los camellos] (vv. 249-250), y en tercer lugar, se

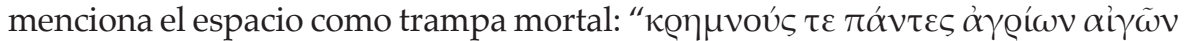

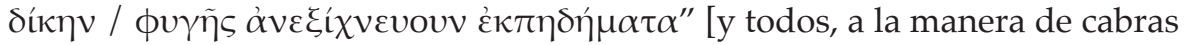
salvajes, / buscaban lugares escarpados 'como saltos de huida'] (vv. 251-252). Al percartarse de su propia trampa, los persas reaccionan desordenadamente y esto los coloca en una situación ridícula de desconcierto muy bien expresada

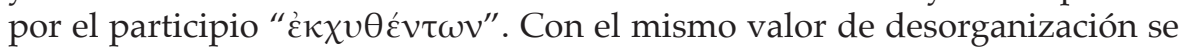
utiliza el adjetivo " $\alpha \tau \alpha \alpha \kappa \epsilon \omega v^{\prime}$ " [desordenados] del verso 267 introducido por el adverbio "oü $\tau \omega \varsigma$ " que, en este caso, sirve como introductor del elemento real en la comparación.

La vinculación del mar, cuyas aguas se agitan violentamente, y el regimiento persa, logra la representación vital de lo narrado de modo de colocar las imágenes ante los ojos de la audiencia. ${ }^{14}$ Es lo que Aristóteles en la Retórica

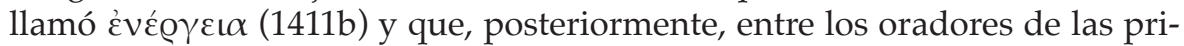
meras centurias se denominó ćvó́ la definición de la ék $\phi \varrho \alpha \sigma \iota \varsigma$ de los manuales de retórica. ${ }^{15}$

\section{La importante función de las formas pronominales}

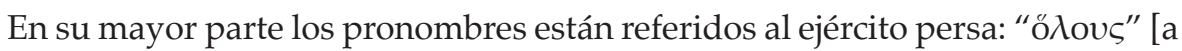

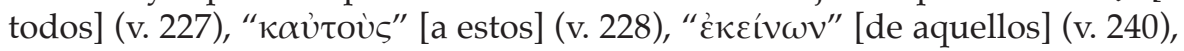

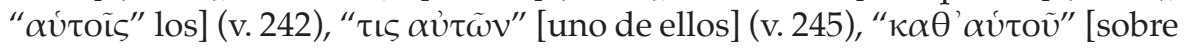

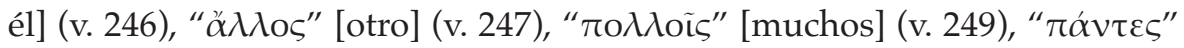

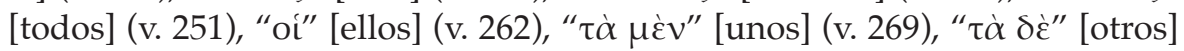

14 Sobre el concepto de 'colocar frente a los ojos del auditorio', además de Aristóteles, ver también: Quintiliano, Inst. 6.2.29-31;8.3.61-63; 9.2.40-41; Cicerón, De or. 3.160; Elsner (2010:26).

15 Cfr. Theon (p.119, l.28). Con escasas variantes fue definido por Hermógenes (sect.10, l.24), Aftonio (p.36, l.23), Nicolás de Mira (p.69, l.11). Marini aclara que la évépyeı se refería a la intensidad de la descripción y esta, a su vez, conducía a la évápveıa, imagen vívida en la mente del receptor. (2019:1). Ver también: Cariboni Killander; Lutas; Strukelj (2014:10-14); Webb (2009:193; 2001:20); Lessing (1960:107-108); Papaiaoannou (2011:57). 


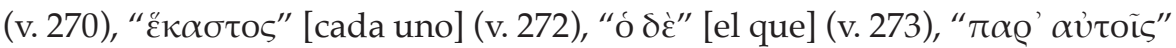
[por ellos] (v. 274). Mientras que los utilizados para referirse a los hombres de Heraclio son muy escasos: " $\pi \tilde{\alpha} \varsigma \tau \iota \varsigma \eta j \mu \tilde{\omega} v^{\prime}$ " [cada uno de nosotros] (v. 258), "H $\mathrm{Hiv} v$ " [para nosotros] (v. 276).

En el primer recuento, vemos que muchos de los pronombres son indefinidos y algunos demostrativos; todos dispuestos de manera de llevar a un primer plano al ejército enemigo y, al mismo tiempo, para dar idea de multitud, de desorden, de distancia, de grandes agrupaciones sin rostro. Este procedimiento de utilizar los pronombres para lograr la sensación de una enumeración imprecisa es utilizado por el poeta como recurso que le permite tomar la distancia del observador, como si estuviera compartiendo la perspectiva del auditorio. En cambio, para referirse al ejército bizantino, emplea, por una parte, muy pocos pronombres, pues quienes están vencidos y en calidad de fugitivos son 'los otros', los que protagonizan la retirada. Los bizantinos sólo observan los resultados de la gran estrategia ideada por su líder, como desde un segundo plano. Por otra parte, los escasos pronombres referidos a las huestes de Heraclio, son personales. Es un 'nosotros' que involucra al mismo tiempo al ejército bizantino, al poeta ${ }^{16} \mathrm{y}$ al auditorio inclusive, pues este último, al inferir cada palabra de lo relatado, se hace partícipe de ese momento de la batalla. Es decir que en las dos situaciones, los pronombres utilizados actúan como marcadores que dan sensación de espacialidad.

\section{Conclusiones}

El propósito del trabajo ha sido contrastar la imagen cristiana de Heraclio constantemente frente a la barbarie persa. Vimos que Pisidia no descuida ninguna palabra que de manera manifiesta o indirecta resalte la idolatría y el atraso del enemigo

Hemos observado cómo la descripción de la batalla es presentada a través de

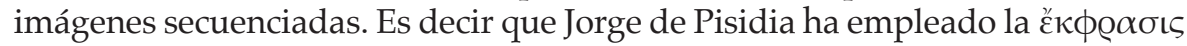
de acuerdo con los manuales tradicionales de retórica, en los cuales no existía una separación entre hecho e imagen, esto es, narración y descripción, sino que tal como lo había hecho Homero muchos siglos antes, narra los acontecimientos de la campaña describiéndolos. Este enfoque logra dar vivacidad

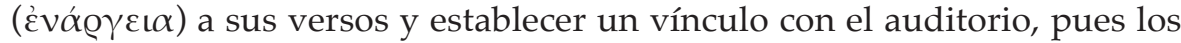
distintos momentos 'descriptos en detalle' se presentan ante él como si estuviera presenciándolos: “Grazie all'esatta riproduzione del reale, che l'oratore riesce a realizzare per mezzo dell'eloquenza, l'ascoltatore potrà ripercorrere il processo imitativo ed avvertire la percezioni e le emozioni che ad esso hanno dato origine" (Manieri, 1998:143).

El poeta, consciente de la importancia de esta campaña militar, pues además de un final exitoso significaba la "ruptura de una sucesión de derrotas continuadas de los ejércitos romanos" (Espejo Jáimez, 2015:158), buscó exaltar cada momento, frente a una élite cortesana, que estaba al tanto de los logros de Heraclio. Sobre esto afirma Howard Johnston: "Hence to he could asume that his audience would be familiar with the campaign" (2010:20).

16 Según Tartaglia (1988:97), el poeta ha estado presente en esta expedición y lo fundamenta con dos versos principalmente: E.P. II. 126 y III. 131. 
Con extrema habilidad y seguramente con absoluto manejo de la modulación de su voz, ${ }^{17}$ Jorge de Pisidia ha relatado mezclando cada acción con imágenes elocuentes, ha utilizado el espacio como herramienta principal para crear credibilidad ${ }^{18}$ y de este modo apelar, ante todo, a la imaginación del auditorio. La

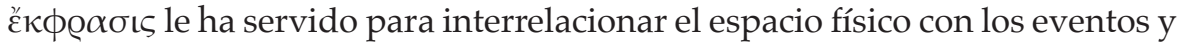
darles un carácter simbólico. De este modo, además de enaltecer la figura de su mecenas, ha logrado transmitir de manera elusiva ideas políticas y religiosas.

17 Cfr. Cavallo (2017:96).

18 Cfr. Messis; Nilsson (2018:29); Bal (1990:135). 


\section{Q Bibliografía}

\section{Fuentes}

» Felten, J. (ed.) (1913). Nicolai progymnasmata. Rhetores Graeci XI. Leipzig: Teubner, $1-79$.

» Fogginus, P.F. (ed.) (1777). Corporis Historiae Byzantinae. Nova Appendix. Opera Georgii Pisidae Theodosii Diaconi et Corippi Africani Grammatici. Roma: Benedictum Francesium.

» García Yebra, V. (ed.) (1992). Poética de Aristóteles. Madrid: Gredos.

» Pertusi, A. (ed. y trad.) (1959). Giorgio Di Pisidia. Poemi. I Panegirici Epici. Ettal: BuchKunstverlag.

» Rabe, H. (ed.) (1913). Hermogenis opera. Rhetores Graeci VI. Leipzig: Teubner, (repr. 1969).

" Rabe, H. (ed.) (1926). Aphthonii progymnasmata. Rhetores GraeciX. Leipzig: Teubner, 1-51.

» Rackham, M. (ed.). Cicero. On the orator. Book III. Cambridge: Harvard University Press.

" Tartaglia, L. (trad.) (1988). Carmi di Giorgio di Pisidia. Torino: Unione Tipografico Editrice Torinese.

"Spengel, L. (ed.) (1854) Theon Progymnasmata. Rhetores Graeci II. Leipzig: Teubner, 59-130.

" Tovar, A. (ed.). (1990). Aristóteles. Retórica. Madrid: Centro de Estudios Constitucionales.

»Winterbottom, M. (ed.) (1970). Quintiliani M. Fabi. Institutionis Oratoriae Libri Duodecim. Oxford: Oxford University Press.

\section{Estudios}

» Bal, M. (1990). Teoría de la narrativa. (Una introducción a la narratología). Madrid: Cátedra.

» Barthes, R. (1989). The Rustle of Language. Berkeley: University of California Press.

» Beaujour, M. (1981) "Some Paradoxes of Description", Yale French Studies 61, 27-59. https://www.jstor.org/stable/2929876; obtenido el 17/05/2019.

» Bourbouhakis, E.; Nilsson, I. (2010). "Byzantine Narrative: the Form of Storytelling in Byzantium". En: James, L. (ed.). A Companion to Byzantium. Malden: Wiley-Blackwell, 263-275.

» Browning, R. (1983). Medieval and Modern Greek. Cambridge: Cambridge University Press.

» Burkert, W. (2007) Religión griega arcaica y clásica. Madrid: Abada. 
" Cariboni Killander, C.; Lutas, L.; Strukelj, A. (2014). "A New Look on Ekphrasis: an Eye-tracking Experiment on a Cinematic Example". Ekphrasis. Images, Cinema, Theatre. Media 12.2, 10-31. https://portal. research.lu.se/portal/en/.../a ekphrasis... cinematic.../export. html, obtenido el 10/04/2019.

» Cavallo, G. (2017). Leer en Bizancio. Buenos Aires: Ampersand.

»Crespo, E.; Conti, L.; Maquieira, H. (2003). Sintaxis del Griego Clásico. Madrid: Gredos.

"Cristensen, J. (2009). "La ékfrasis homérica y la copa de Néstor", Revista Vértebra 11, 7-15. https://revistavertebra.files.wordpress.com/2009/10/031; obtenido el 29/04/2019.

" D'Angelo, F. (1998). "The Rhetoric of Ekphrasis", JAC 18, 439-447. http://www.jstor. org/stable/20866203; obtenido el 05/02/2019.

» de Jong, I. (2014). "Narratology and Epic". En: Narratology Classics. A practical guide. Oxford: Oxford University Press, 1-38.

"Elsner, J. (2002). "Introduction the genres of ekphrasis", Ramus 31, 1-18. https:// www.academia.edu/.../_The_Genres_of_Ekphrasis_Ramus_31_2002, obtenido el 14/05/2019.

"Elsner, J. (2010). "Art History as Ekphrasis", Art History 33.1, 10-27. https://is. muni.cz/el/1421/podzim2012/DU2544m/j.1467-8365.2009.00720.x, obtenido el 10/05/2019.

»Espejo Jáimez, G. (2015). Significación literaria e ideológica en la tradición bizantina de los Panegíricos Épicos de Jorge de Pisidia. Granada: Universidad de Granada.

"Eterovic, M. (1970). Lexicón. Diccionario de raíces. Córdoba: Profesorado Salesiano Miguel Rua.

"Fowler, D. (1991). "Narrate and Describe: The Problem of Ekphrasis", JRS 81, 25-35. http://www.jstor.org/stable/300486; obtenido el 02/01/2014.

" Francis, J. (2009). "Metal maidens, Achilles' Schield, and Pandora: the beginnings of Ekphrasis", AJPh 130.1, 1-23. https://www.jstor.org/stable/i20616163; obtenido el 18/06/2019.

» Fränkel, H. (1993). Poesía y Filosofía de la Grecia Arcaica. Madrid: Fuenlabrada.

» Genette, G. (1970). "Fronteras del relato". En: AA.VV. Análisis estructural del relato. Buenos Aires: Editorial Tiempo Contemporáneo, 191-208.

» Genette, G. (1979). Narrative Discourse: An Essay in Method. New York: Cornell University Press.

" Genette, G. (1982). Figures of Literary Discourse. New York: Columbia UP.

» Genette, G. (1989). Figuras III. Barcelona: Lumen. (Manzano, C. trad.)

» Genette, G. (1993). Ficción y dicción.Barcelona: Lumen. (Manzano, C. trad.)

" Genette, G. (1998). Nuevo discurso del relato. Madrid: Cátedra.

»González Rendón, D. (2008). "Acerca de los Progymnásmata", Escritos 16.36, 260282. En: www.plagios.org/wp.../Anexo-2-Acerca-de-los-progymnasmata; obtenido el 19/10/2018. V. $16, n^{\circ} 36,260-282$.

"Gregory, T. (2017). "Narrative of the Byzantine Landscape". En: Burke, J. (ed.). Byzantine Narrative. Papers in Honour of Roger Scott. Leiden-Boston: Brill, 481-497.

» Hagstrum, J. (1958). The Sister Arts: The Tradition of Literary Pictorialism and English Poetry from Dryden to Gray. Chicago: The University of Chicago Press. 
" Heffernan, J. (1991). "Ekphrasis and Representation", New Literary History22.2, 207316. http://www.jstor.org/stable/469040; obtenido el 11/11/2015.

» Heffernan, J. (1993). Museum of Word. The Poetics of Ekprhasis from Homer to Ashberry. Chicago: The University of Chicago Press.

» Heffernan, J. (2015). "Ekphrasis: Theory". En: Rippl, G. (ed.). Handbook of Intermediality. Berlin-Boston: Walter de Gruyter, 35-49.

" Howard-Johnston, J. (2010). Witnesses to a World Crisis. Historians and Histories of the Middle East in the Seventh Century. New York: Oxford University Press.

" Koopman, N. (2018). Ancient Greek ekphrasis: Between description and narration: Five Linguistic and narratological Case Studies. Leiden: Brill. https://dare.uva.nl/ personal/pure/en/publications/ancient-greek-ekphrasis-between-descriptionand-narration.(511a0974-315e-4072-b9fe-c9314c9968).html; obtenido el 10/04/ 2019.

» Lessing, G. (1960). Laocconte. O los límites de la pintura y de la poesía. México: UNAM. (Ragio, A. trad.)

» López Cruces, J.; Papadopoulou, P. (eds.) (2017). Sánchez Egea J. La lengua Medieval. Miscelánea de estudios bizantinos y griegos 3. Granada: Centro de Estudios Bizantinos, Neogriegos y Chipriotas.

» Manieri, A. (1998). L'immagine poetica nella teoria debli antichi. Phantasia ed enargeia. Pisa-Roma: Istituti Editoriali e Poligrafici Internazionali.

» Marini, N. (s/F). "L'źvápveıa o evidentia nella tradizione retorica greca e latina". MediaClassicas/d. www.loescher.it/mediaclassica; obtenido el 23/05/2019.

" Messis, Ch.; Nilsson, I. (2018). "Byzantine storytelling and modern narratology: an introduction". En: Messis, Ch.; Mullett, M.; Nilsson, I. (eds.). Storytelling in Byzantium. Narratological approaches to Byzantine texts and images. Uppsala: Uppsala Universiteit, 1-15.

»Nestlé, W. (1961). Historia del pensamiento griego. Barcelona: Ariel.

»Papaiaoannou, S. (2011). "Byzantine Enargeia and Theories of Representation". En: Vavrínex, V., Odorico, P., et Drbal, V. (eds.). EKPHRASIS. La représentation des monuments dans les littératures byzantine et byzantino-slaves. Réalités et imaginaires. Prague: L'institute slave de l' Académie des sciences de la République Tchèque, 48-60.

" Spitzer, L. (1962). "The 'Ode' on a Grecian Urn, or content vs metagrammar". En: Hatcher, A (ed.). Essays on English and American Literature. Princeton: Princeton University Press, 67-97.

"Trapp, E. (2001). Lexikon Zur Byzantinischen Gräzität. Wien: Verlag Der Österreichischen Akademie Der Wissenschaften.

"Veikou, M. (2018). "'Telling spaces' in Byzantium: ekphraseis, place-making and 'thick description'". En: Messis, Ch. Mullett, M., Nilsson, I. (eds.). Storytelling in Byzantium. Narratological approaches to Byzantine texts and images. Uppsala: Uppsala Universiteit, 15-32.

» Velasco López (2004). "Lecturas del mito de Meleagro", Minerva 17, 31-84.

"Webb, R. (1999). "The aesthetics of sacred space: narrative, metaphor, and motion in ekphraseis of church buildings". En: Jeffreys, E.; Haldon, J.; Cormack, R. (eds.) The Oxford Handbook of Byzantine Studies, 59-74. https://www.jstor.org/stable/1291794; obtenido el 05/04/2019. 
» Webb, R. (1999). "Ekphrasis ancient and modern: The invention of a genre", Word \& Image 15.1, 7-18.

»Webb, R. (2016). Ekphrasis, Imagination and Persuasion in Ancient Rhetorical Theory and Practice. New York: Routledge.

"Webb. R. (2011). "Ekphraseis of buildings in Byzantium: theory and practice". En: Vavrínex, V., Odorico, P., et Drbal, V. (eds.). EKPHRASIS. La représentation des monuments dans les littératures byzantine et byzantino-slaves. Réalités et imaginaires. Prague: L'institute slave de l'Académie des sciences de la République Tchèque, 2032. 
